\title{
Analysis of $E G F R$ mutation status in tissue and plasma for predicting response to EGFR-TKIs in advanced non-small-cell lung cancer
}

\author{
YUYAN WANG* ${ }^{*}$ JIANCHUN DUAN* , HANXIAO CHEN, HUA BAI, TONGTONG AN, \\ JUN ZHAO, ZHIJIE WANG, MINGLEI ZHUO, SHUHANG WANG and JIE WANG \\ The Key Laboratory of Carcinogenesis and Translational Research (Ministry of Education), \\ Department of Thoracic Medical Oncology, Beijing Institute of Cancer Research, Beijing 100142, P.R. China
}

Received July 9, 2015; Accepted November 17, 2016

DOI: $10.3892 / \mathrm{ol} .2017 .5740$

\begin{abstract}
The detection of mutations in the epidermal growth factor receptor (EGFR) gene in tumor tissues has been established as the gold standard for predicting the efficacy of treatment with EGFR-tyrosine kinase inhibitors (EGFR-TKIs) in advanced non-small-cell lung cancer (NSCLC). The current study aimed to investigate whether the presence of co-existing EGFR mutations in tumor tissue and in cell-free tumor DNA (ctDNA) in the plasma predicts a more favorable outcome of EGFR-TKI treatment in advanced NSCLC. A total of 287 NSCLC patients who had undergone EGFR-TKI treatment were enrolled and stratified into four subgroups: Wild-type EGFR in plasma and tissue specimens (B-/T-); mutated EGFR in plasma and tissue specimens $(\mathrm{B}+/ \mathrm{T}+)$; mutated EGFR in only in plasma samples (B+/T-); or mutated EGFR in only tissue specimens $(\mathrm{B}-/ \mathrm{T}+)$. EGFR mutations were tested using denaturing high-performance liquid chromatography and confirmed by amplification-refractory mutation system analysis. Of the 287 patients, 101 had mutations in both tissue and plasma samples and 103 had mutation in either tissue $(n=65)$ or plasma $(n=38)$. The median progression-free survival (mPFS) times were 9.2 and 2.0 months in the $\mathrm{B}+/ \mathrm{T}+$ and $\mathrm{B}-/ \mathrm{T}-$ groups, respectively. The mPFS times were 7.9 months in the $\mathrm{B}-/ \mathrm{T}+$ group and 11.9 months in the $\mathrm{B}+/ \mathrm{T}$-group $(\mathrm{P}=0.001)$. Among the 187 patients with available pre-EGFR-TKI plasma samples, 70 received first-line EGFR-TKI treatment, and the mPFS
\end{abstract}

Correspondence to: $\mathrm{Dr}$ Jie Weng, The Key Laboratory of Carcinogenesis and Translational Research (Ministry of Education), Department of Thoracic Medical Oncology, Beijing Institute of Cancer Research, 52 Fucheng Road, Beijing 100142, P.R. China

E-mail: zlhuxi@163.com

*Contributed equally

Key words: epidermal growth factor receptor mutation, plasma detection, response predicting, EGFR-tyrosine kinase inhibitors, non-small cell lung cancer in the $\mathrm{B}+/ \mathrm{T}+$ group was longer than in the $\mathrm{B}-/ \mathrm{T}+$ or $\mathrm{B}+/ \mathrm{T}$ groups (18.8 vs. 9.4 vs. 6.9 months; $\mathrm{P}=0.003)$. In second-line setting of EGFR-TKI therapy, the groups of patients with EGFR mutation in ctDNA, regardless of the mutation status in the tissues, exhibited longer mPFS times compared with the $\mathrm{B}-/ \mathrm{T}+$ group (10.0 vs. 5.8 months; $\mathrm{P}=0.044)$. The results suggest that co-existence of EGFR mutations in tissue and ctDNA predict longer PFS times for NSCLC patients who receive first-line EGFR-TKI therapy. In addition, real-time detection in ctDNA is an excellent predictor for the efficacy of second- or higher line EGFR-TKI therapy.

\section{Introduction}

Lung cancer is the leading cause of cancer-associated mortality worldwide $(1,2)$. Epidermal growth factor receptor (EGFR)-tyrosine kinase inhibitors (TKIs) have significantly improved the outcome of advanced NSCLC, particularly in patients that carried EGFR mutation, as first-line, second-line or maintenance therapeutic strategies (3-5). The predictive value of EGFR-TKI-sensitive mutations, including an in-frame deletion in exon 19 and the missense mutation L858R in exon 21 , has been generally acknowledged and widely utilized in clinical practice (6-8). At present, determination of EGFR mutations in tissue samples remains the gold standard. Additionally, a number of studies have reported the use of liquid biopsy to detect EGFR mutations, in an effort to explore more convenient and real-time solutions for directing clinical decisions regarding EGFR-TKI treatment (9-14). However, the issue of how to explain the observed discordance between EGFR mutations in tissues and plasma DNA, and how to use this information to predict treatment efficiency and prognosis, are still being investigated.

A finite quantity of cell-free tumor DNA (ctDNA) is released into the plasma of peripheral blood in patients with advanced lung cancer, and may be used as a diagnostic marker (15). Plasma DNA is easily obtained and has been demonstrated to be a reasonable complement to tumor tissues in patients in whom biopsies are difficult or who require repeat testing for mutations associated with sensitivity or resistance to EGFR-TKIs $(13,16)$. Various studies have 
confirmed that ctDNA in advanced NSCLC patients has the same genetic characteristics as primary tumor genomic DNA, and has an EGFR mutation rate consistent with tumor tissues $(60-80 \%)(11-13,17)$. The $20-40 \%$ variation in mutation status between blood and tissue samples likely results from the relatively low-sensitivity detection methods for plasma DNA, the heterogeneity of genetic abnormalities in tumors, the lower levels of free circulating DNA, or the dilution of DNA derived from non-cancerous tissues (13).

Improved understanding of EGFR mutation heterogeneity in tumor tissues and the genetic changes associated with EGFR-TKI sensitivity or resistance during treatment or disease progression $(18,19)$ has increased the value of dynamic monitoring of EGFR mutations in the peripheral blood. Bai et al (18) found that the EGFR mutation detection rate in plasma DNA significantly decreased from $34.5 \%$ (91/264) prior to chemotherapy to $23.1 \%(61 / 264)$ following treatment $(\mathrm{P}<0.001)$, and that $30.9 \%$ of patients presented with dynamic alterations of EGFR mutation during the process of chemotherapy. Correspondingly, 10-38\% (30/79) of NSCLC patients possessed intratumor EGFR mutation heterogeneity, which was thought to be associated with the dynamic alteration of EGFR mutations $(18,19)$. Thus, the traditional concept that EGFR mutation detection in primary tumor tissues is the gold standard has been challenged based on the existence of spatial (primary and metastatic lesions) and temporal (pre- and post-treatment) heterogeneity of the EGFR mutations. ctDNA originates from apoptotic and necrotic cancer cells from various tumor regions, and may be able to avoid or overcome intratumor heterogeneity. Therefore, we speculated that the consistency or inconsistency of EGFR mutations detected in tumor tissues and ctDNA may possess different clinical significance. EGFR mutation testing in both tissue and plasma ctDNA samples may be more powerful for predicting response to EGFR-TKI therapy, particularly for treatment-naive patients.

The present study investigated whether EGFR mutations detected in both tissue and plasma samples, compared to detection in a single sample, had different predictive value with regard to the benefit of EGFR-TKI treatment in patients with advanced NSCLC in various therapeutic settings. In addition, we attempted to determine a simple and effective method for predicting responses to second- or higher lines EGFR-TKI treatments when repeat biopsy couldn't be performed.

\section{Materials and methods}

Patients. Informed consent was obtained from all patients prior to the study, which was approved by the Institutional Ethics Committee at Peking University Cancer Hospital (Beijing, China). All participants met the following criteria: i) Had received EGFR-TKI treatment at any time during the course of their disease, up until disease progression [gefitinib (250 mg per day, orally) and erlotinib (150 mg per day, orally)]; ii) had surgically resected or biopsied [computed tomography (CT)-guided or bronchoscopy-guided] tumor tissues that were viewed by pathologists for confirmation of NSCLC tumor histology and tumor content $\geq 15 \%$; iii) had plasma samples collected prior to or during EGFR-TKI treatment; and iv) had a complete record of clinical follow-up information. All procedures followed were in accordance with the ethical standards of the responsible committee on human experimentation (institutional and national) and with the Helsinki Declaration.

Sample collection and processing. Blood from the patients was collected in anti-coagulation tubes, and plasma DNA was extracted according to a previously reported method (13). DNA was also extracted from $5 \mu$ m-thick tissue sections $(n=5$ for each tumor case) using the E.Z.N.A FFPE DNA Kit (Omega Bio-Tek, Inc., Norcross, GA, USA). The quality and concentration of extracted DNA derived from plasma or tissue samples were determined using a NanoDrop 2000 spectrophotometer (Thermo Fisher Scientific, Inc., Wilmington, DE, USA).

Mutation analysis and qualitative control. All tissue samples included in the study were required to have $\geq 15 \%$ tumor content. Extracted DNA from matched tissues and blood samples were analyzed in the same conditions to equalize detection conditions. EGFR exon 19 deletions or exon 21 substitution mutations were screened using a denaturing high-performance liquid chromatography (DHPLC) method (13). An amplification-refractory mutation system (ADx-ARMS®; Amoy Diagnostics Co., Ltd, Xiamen, China) was used to confirm the results in lung adenocarcinoma samples that exhibited wild-type EGFR on DHPLC. For the B+/T- group, it was necessary that the two methods of EGFR detection be used to confirm the EGFR mutation status in the tissues and blood samples.

Statistical analysis. Frequency tabulation and summary statistics are provided to characterize the data distributions. McNemar's test was applied to compare the mutation statuses between tissue and plasma. All categorical variables were analyzed with $\chi^{2}$ tests, unless a small sample size $(<5)$ required the use of Fisher's exact test. Progression-free survival (PFS) was analyzed using the Kaplan-Meier method and compared between different groups using the log-rank test, follwed by the Bonferroni correction. Comparison of overall response rates (ORRs) between different groups was performed using $\chi^{2}$ tests. A multivariate Cox proportional hazards regression model was used to evaluate independent predictive factors associated with PFS. Statistical significance was set at $\mathrm{P}<0.05$. Two-sided tests were performed in all settings, and all calculations were performed using SAS Version 10.0 (SAS Institute, Inc., Cary, NC, USA).

\section{Results}

Patients and specimen characteristics. The sociodemographic and clinical characteristics of the 287 patients are presented in Table I. In 187 patients, plasma ctDNA and tissues were obtained prior to EGFR-TKI therapy, while the other 100 patients provided blood samples during EGFR-TKI therapy. Of the 187 patients, 86 matched tissue (primary or metastatic) and blood samples were obtained at the same time point prior to EGFR-TKI therapy, including 70 patients who were administered first-line EGFR-TKI treatment and 16 patients who received second or higher-line EGFR-TKI treatment who had repeat biopsy samples and real-time blood samples. In the other 101 of 187 cases, tissues and blood samples were obtained at different time points, but all were obtained prior to EGFR-TKI therapy. 
Table I. Clinical and disease characteristics of all 287 patients, and of the 187 patients for whom plasma and tissue specimens were obtained prior to EGFR-TKI therapy.

\begin{tabular}{|c|c|c|}
\hline \multirow[b]{2}{*}{ Variable } & \multicolumn{2}{|c|}{ No. of patients (\%) } \\
\hline & $\begin{array}{c}\text { All } \\
(n=287)\end{array}$ & $\begin{array}{l}\text { Pre-EGFR-TKI }{ }^{\mathrm{a}} \\
\qquad(\mathrm{n}=187)\end{array}$ \\
\hline \multicolumn{3}{|l|}{ Age, years } \\
\hline$<65$ & $142(49.5)$ & $91(48.7)$ \\
\hline$\geq 65$ & $145(50.5)$ & $96(51.3)$ \\
\hline \multicolumn{3}{|l|}{ Gender } \\
\hline Male & $133(46.3)$ & $83(44.4)$ \\
\hline Female & $154(53.7)$ & $104(55.6)$ \\
\hline \multicolumn{3}{|l|}{ Disease stage } \\
\hline IIIB & 57 (19.9) & $31(16.6)$ \\
\hline IV & $230(80.1)$ & $156(83.4)$ \\
\hline \multicolumn{3}{|l|}{ Smoking history } \\
\hline Smoker & $107(37.3)$ & $64(34.2)$ \\
\hline Never smoker & $179(62.4)$ & $116(62.0)$ \\
\hline Unknown & $1(0.3)$ & $7(3.7)$ \\
\hline \multicolumn{3}{|l|}{ Histological type } \\
\hline Adenocarcinoma & $249(86.8)$ & $164(87.7)$ \\
\hline Non-adenocarcinoma ${ }^{\mathrm{b}}$ & $38(13.2)$ & $23(12.3)$ \\
\hline \multicolumn{3}{|c|}{ 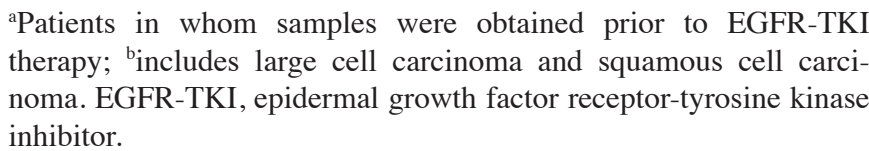 } \\
\hline
\end{tabular}

Consistency of EGFR mutation status between tissue and plasma. Of the 287 patients, 51.6\% (148/287) and $42.2 \%$ $(121 / 287)$ had EGFR mutations in the tumor tissues (T+) and plasma $(\mathrm{B}+)$, respectively. In $28.9 \%$ of patients $(83 / 287)$, mutations were detected in both the tumor tissue and the plasma $(\mathrm{B}+/ \mathrm{T}+)$, while $22.6 \%(65 / 287)$ had mutations only in tissue (B-/T+) and 13.2\% (38/287) had mutations only in plasma DNA (B+/T-). Therefore, the consistency of EGFR mutation status between plasma DNA and tissue (B+/T+ plus B-/T- groups) was $64.1 \%(184 / 287)$.

Given that EGFR mutation status consistency between tissue and peripheral blood may be influenced by the timing of sampling, the 187 patients who had tissues and blood samples collected prior to EGFR-TKI therapy were further analyzed. These patients were divided into three subgroups based on the original tissue samples: Group 1 underwent surgical resection of tumor tissues $(24.6 \%$; 46/187); Group 2 underwent primary tumor biopsy by bronchoscopy- or CT-guided needle biopsy (42.2\%; 79/187); and Group 3 had tumor samples collected from metastatic lesion biopsies $(33.2 \%$; 62/187). Patients were also divided into another two subgroups based on EGFR-TKI therapy schedule: Group 4 received first-line EGFR-TKI therapy $(37.4 \%$; 70/187) and Group 5 received EGFR-TKIs as second or higher-line treatment or $(62.6 \% ; 117 / 187)$. EGFR mutation statuses among the five subgroups are presented in Table II. The rates of consistency of EGFR mutation status
Table II. EGFR mutation statuses of plasma DNA and tissues in patients for whom plasma and tissue specimens were obtained prior to EGFR-TKI therapy $(n=187)$, subdivided by origin of tissue sample or the therapy line of EGFR-TKIs.

A, Patients subdivided by tissue origin

\begin{tabular}{lccr}
\hline $\begin{array}{l}\text { EGFR } \\
\text { mutation status }\end{array}$ & $\begin{array}{c}\text { Group 1, } \\
\mathrm{n}(\%)\end{array}$ & $\begin{array}{c}\text { Group 2, } \\
\mathrm{n}(\%)\end{array}$ & $\begin{array}{c}\text { Group 3, } \\
\mathrm{n}(\%)\end{array}$ \\
\hline $\mathrm{B}-/ \mathrm{T}-$ & $16(34.8)$ & $32(40.5)$ & $22(35.5)$ \\
$\mathrm{B}-/ \mathrm{T}+$ & $15(32.6)$ & $18(22.8)$ & $18(29.0)$ \\
$\mathrm{B}+/ \mathrm{T}-$ & $2(4.3)$ & $5(6.3)$ & $7(11.3)$ \\
$\mathrm{B}+/ \mathrm{T}+$ & $13(28.3)$ & $24(30.4)$ & $15(24.2)$ \\
Total & $46(100)$ & $79(100)$ & $62(100)$ \\
\hline
\end{tabular}

B, Patients subdivided by EGFR-TKI therapy line

\begin{tabular}{lcc}
\hline $\begin{array}{l}\text { EGFR } \\
\text { mutation status }\end{array}$ & $\begin{array}{c}\text { Group 4, } \\
\mathrm{n}(\%)\end{array}$ & $\begin{array}{c}\text { Group 5, } \\
\mathrm{n}(\%)\end{array}$ \\
\hline $\mathrm{B}-/ \mathrm{T}-$ & $24(34.3)$ & $47(40.2)$ \\
$\mathrm{B}-/ \mathrm{T}+$ & $23(32.9)$ & $30(25.6)$ \\
$\mathrm{B}+/ \mathrm{T}-$ & $5(7.1)$ & $8(6.8)$ \\
$\mathrm{B}+/ \mathrm{T}+$ & $18(25.7)$ & $32(27.4)$ \\
Total & $70(100)$ & $117(100)$
\end{tabular}

Group 1, patients received surgical resection of primary tumor tissue; Group 2, patients underwent primary tumor biopsy (bronchoscopy- or computed tomography-guided needle biopsy); Group 3 , tumor samples were obtained from metastatic lesion biopsy; Group 4, patients received EGFR-TKI as first-line therapy; Group 5, patients received EGFR-TKIs as second or higher-line therapy. EGFR, epidermal growth factor receptor; TKI, tyrosine kinase inhibitor; B-, wild-type EGFR gene in plasma DNA; T-, wild-type EGFR gene in tumor tissue; $\mathrm{B}+$, mutant type EGFR gene in plasma DNA; T+, mutant type EGFR gene in tumor tissue.

between peripheral blood and tissues from lung cancer surgical resection, primary lung tumor biopsy and metastatic lesion biopsy were $63.1,70.9$ and $59.7 \%$, respectively $(\mathrm{P}=0.711)$.

Predictive values of various EGFR mutation statuses in tissue and plasma for EGFR-TKI efficacy. All 287 patients commenced gefitinib or erlotinib treatment between January 2005 and December 2012. The final follow-up date was December 31st, 2013, and the median follow-up duration was 43.8 months (range, 1.8 to 153.2 months). A total of 232 patients exhibited disease progression and 145 patients succumbed to the disease. In the first-line setting, the ORRs to EGFR-TKI therapy in the $\mathrm{B}-/ \mathrm{T}-, \mathrm{B}-/ \mathrm{T}+, \mathrm{B}+/ \mathrm{T}$ - and $\mathrm{B}+/ \mathrm{T}+$ groups, were $25,78.3,60.0$ and $89.9 \%$, respectively $(\mathrm{P}=0.014)$. In patients who received EGFR-TKIs as second-line or subsequent therapies, the ORRs were $17.4,50.0,57.1$ and $67.7 \%$, respectively ( $\mathrm{P}=0.001$; Table III).

In the $\mathrm{B}+/ \mathrm{T}+$ and $\mathrm{B}-/ \mathrm{T}-$ groups, the median PFS (mPFS) times were 9.2 months [95\% confidence interval (CI), 6.3-12.1 months] and 2.0 months (95\% CI, 1.3-2.7 months), respectively. In the groups with single-sample mutation, the 
Table III. Response rates of patients to EGFR-TKIs as first-line or second-line and higher therapy in 187 patients with various EGFR mutation statuses of plasma and tissue samples.

TKI therapy line and response

EGFR mutation status in tissue and blood, n $(\%)$

\begin{tabular}{lccccc}
\hline First-line & & & & \\
Total & 24 & 23 & 5 & 18 & 0.0149 \\
ORR & $6(25.0)$ & $17(73.9)$ & $3(60.0)$ & $16(88.9)$ & $42(60.0)$ \\
DCR & $13(54.2)$ & $20(87.0)$ & $4(80.0)$ & $16(88.9)$ & $53(75.7)$ \\
PD & $11(45.8)$ & $3(13.0)$ & $1(20.0)$ & $2(11.1)$ & $17(24.3)$ \\
Second-line and higher & 47 & 30 & 8 & 32 & $50(42.7)$ \\
ORR & $8(17.0)$ & $15(50.0)$ & $4(50.0)$ & $23(71.9)$ & $84(71.8)$ \\
DCR & $26(55.3)$ & $20(66.7)$ & $7(87.5)$ & $31(96.9)$ & $33(28.2)$ \\
PD & $21(44.7)$ & $10(33.3)$ & $1(12.5)$ & $1(3.1)$ & \\
\hline
\end{tabular}

P-values show ORR vs. PD. EGFR, epidermal growth factor receptor; TKI, tyrosine kinase inhibitor; B-, wild-type EGFR gene in plasma DNA; T-, wild-type EGFR gene in tumor tissue; $\mathrm{B}+$, mutant type EGFR gene in plasma DNA; T+, mutant type EGFR gene in tumor tissue; ORR, overall response rate; DCR, disease control rate; PD, progressive disease.

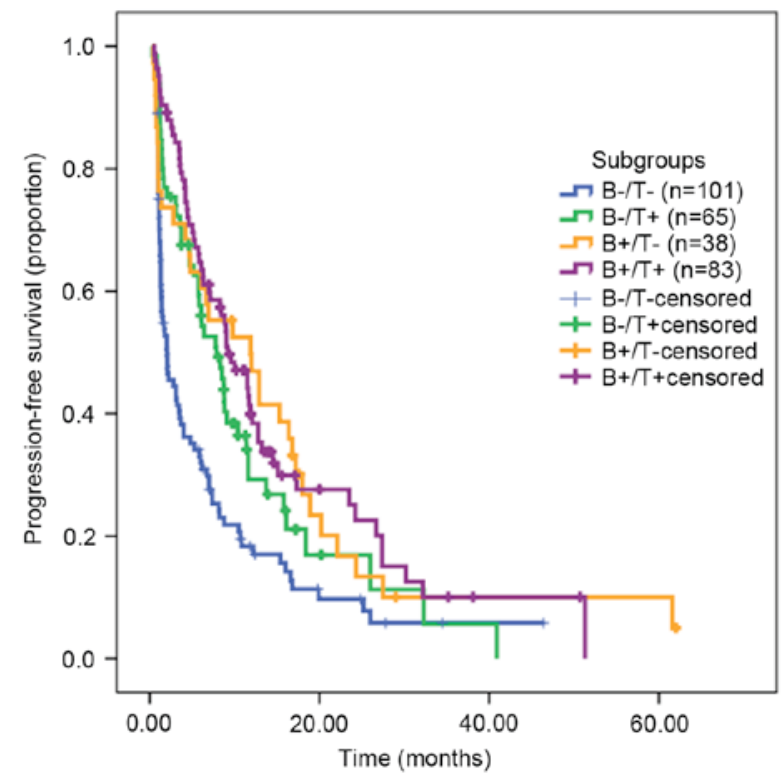

Figure 1. Progression-free survival curves for 287 patients treated with gefitinib or erlotinib with different EGFR mutation statuses measured in tumor tissue and total plasma DNA $(\mathrm{P}<0.001)$. EGFR, epidermal growth factor receptor; B-, wild-type EGFR gene in plasma DNA; T-, wild-type EGFR gene in tumor tissue; $\mathrm{B}+$, mutant type EGFR gene in plasma DNA; T+, mutant type EGFR gene in tumor tissue.

mPFS times were 7.9 months for the B-/T+ group (95\% CI, 5.1-10.6 months) and 11.9 months for the B+/T- group (95\% CI, 3.3-20.5 months) ( $\mathrm{P}=0.001)$. Survival curves for PFS and overall survival (OS) are presented in Figs. 1 and 2. The B+/Tsubgroup had prolonged PFS times compared to the other three subgroups; this difference was significant compared with the $\mathrm{B}-/ \mathrm{T}$ - group $(\mathrm{P}=0.009)$, but not compared with the $\mathrm{B}+/ \mathrm{T}+$ and $\mathrm{B}-\mathrm{T}+$ groups $(\mathrm{P}=0.321$ and $\mathrm{P}=0.992$, respectively).

Of the 187 patients with available pre-EGFR-TKI plasma samples, 70 received EGFR-TKIs as first-line therapy and 117 received this as second-line or subsequent therapy. In

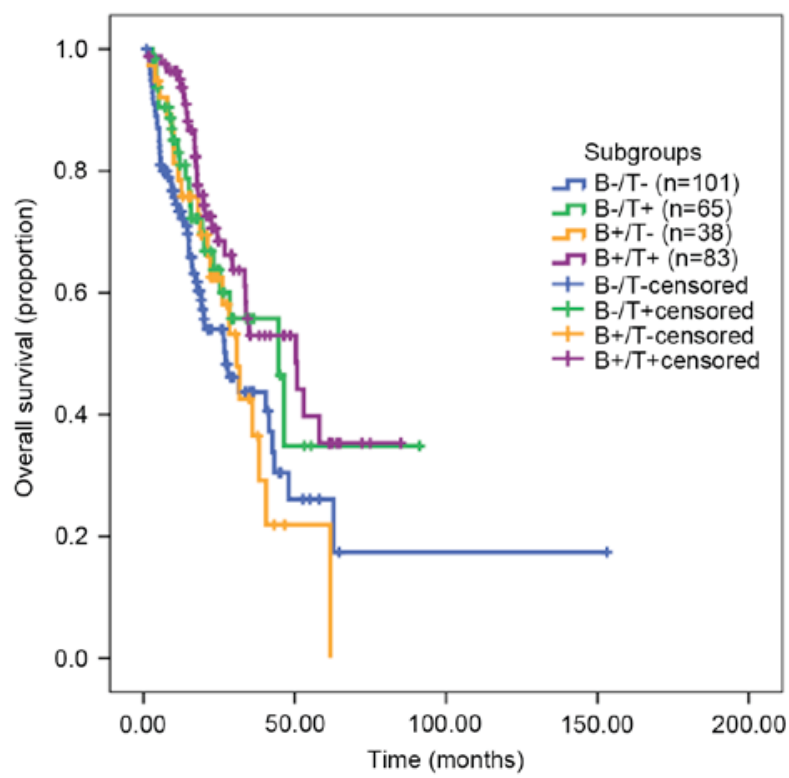

Figure 2. Overall survival curves for 287 patients treated with gefitinib or erlotinib with different EGFR mutation statuses measured in tumor tissue and total plasma DNA $(\mathrm{P}=0.026)$. EGFR, epidermal growth factor receptor; $\mathrm{B}$-, wild-type EGFR gene in plasma DNA; T-, wild-type EGFR gene in tumor tissue; $\mathrm{B}+$, mutant type EGFR gene in plasma DNA; $\mathrm{T}+$, mutant type EGFR gene in tumor tissue.

the first-line setting, PFS times in the $\mathrm{B}+/ \mathrm{T}+$ group $(\mathrm{n}=18)$ were better than in the B-/T+ $(n=23)$ or $B+/ T-$ groups $(n=5)$ [18.8 months (95\% CI, 9.4-28.2 months) vs. 9.4 months $(95 \%$ CI, 2.4-16.3 months) vs. 6.9 months (95\% CI, 0.0-15.8 months), respectively; $\mathrm{P}=0.003$; Fig. 3 ; Table IV]. In the second-line or subsequent settings, the patients with EGFR mutation in ctDNA, regardless of the mutation status in tissues (including $\mathrm{B}+/ \mathrm{T}+$ and $\mathrm{B}+/ \mathrm{T}-)$ presented a longer mPFS time compared with the B-/T+ group [10.0 months (95\% CI, 7.0-13.0 months) vs. 5.8 months (95\% CI, 4.6-6.9 months), respectively; $\mathrm{P}=0.044$; Fig. 4; Table IV]. 
Table IV. Association of PFS with EGFR-TKI treatment as first-line or second-line and higher therapy in 187 patients, subdivided by EGFR mutation statuses in plasma and tissue samples.

\begin{tabular}{lrrr}
\hline & \multicolumn{2}{c}{ PFS time, months } & \\
\cline { 2 - 2 } TKI therapy line & Median & $95 \%$ CI & P-value \\
\hline First-line & & & $0.003^{\text {a }}$ \\
B-/T- & 3.1 & $0.0-7.6$ & \\
B-/T+ & 9.4 & $2.4-16.3$ & \\
B+/T- & 6.9 & $0.0-15.8$ & \\
B+/T+ & 18.8 & $9.4-28.2$ & \\
All statuses & 8.1 & $5.0-11.2$ & \\
Second-line and higher & & & 0.091 \\
B-/T- & 3.5 & $1.6-5.4$ & \\
B-/T+ & 5.3 & $3.9-6.8$ & \\
B+/T- & 12.9 & $8.8-16.9$ & \\
B+/T+ & 9.2 & $7.6-10.8$ & \\
All statuses & 6.3 & $3.8-8.9$ & \\
Total & & & $0.001^{\text {a }}$ \\
B-/T- & 2.0 & $1.3-2.7$ & \\
B-/T+ & 7.9 & $5.1-10.6$ & \\
B+/T- & 11.9 & $3.3-20.5$ & \\
B+/T+ & 9.2 & $6.3-12.1$ & \\
All statuses & 7.0 & $5.1-8.9$ & \\
\hline
\end{tabular}

${ }^{\mathrm{a}} \mathrm{P}<0.01$. PFS, progression-free survival; EGFR, epidermal growth factor receptor; TKI, tyrosine kinase inhibitor; CI, confidence interval; B-, wild-type EGFR gene in plasma DNA; T-, wild-type EGFR gene in tumor tissue; $\mathrm{B}+$, mutant type EGFR gene in plasma DNA; T+, mutant type EGFR gene in tumor tissue.

Specimens obtained from primary or metastatic sites with EGFR mutations had significantly better ORRs and PFS responses to EGFR-TKIs than specimens with wild-type EGFR (ORR, $\mathrm{P}=0.003$ and $\mathrm{P}=0.014$; PFS, $\mathrm{P}=0.018$ and $\mathrm{P}=0.018$; data not shown), but these differences were not identified in resected specimens $(\mathrm{ORR}, \mathrm{P}=0.462 ; \mathrm{PFS}, \mathrm{P}=0.757$; data not shown). When coupled with blood samples, $\mathrm{B}+/ \mathrm{T}+$ groups tended to have a longer PFS times than the B+/T- and $\mathrm{B}-/ \mathrm{T}+$ groups in primary or metastatic site biopsies; however, these differences were not statistically significant $(\mathrm{P}>0.05$; data not shown).

\section{Discussion}

Due to its high specificity, which was identified in several retrospective studies $(3,13,17)$, EGFR mutation detection in ctDNA is considered complementary to detection in tissues. The present study demonstrated that, among patients treated with first-line EGFR-TKI, those with co-existing EGFR mutations in tissue samples and ctDNA $(\mathrm{B}+/ \mathrm{T}+)$ had superior PFS times compared with those with EGFR mutations detected only in tissues or ctDNA. However, among those treated with EGFR-TKIs as second-line or subsequent therapy, patients

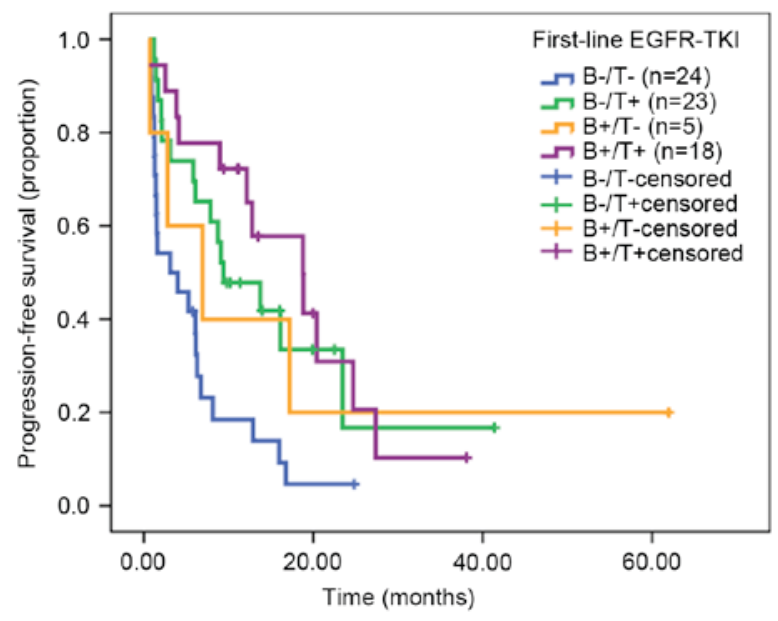

Figure 3. Progression-free survival curves for the 187 patients with different EGFR mutation statuses measured in tumor tissues and concurrent plasma DNA, who were treated by EGFR-TKIs as first-line therapy $(\mathrm{P}=0.003)$. EGFR, epidermal growth factor receptor; TKI, tyrosine kinase inhibitor; B-, wild-type EGFR gene in plasma DNA; T-, wild-type EGFR gene in tumor tissue; $\mathrm{B}+$, mutant type EGFR gene in plasma DNA; T+, mutant type EGFR gene in tumor tissue.

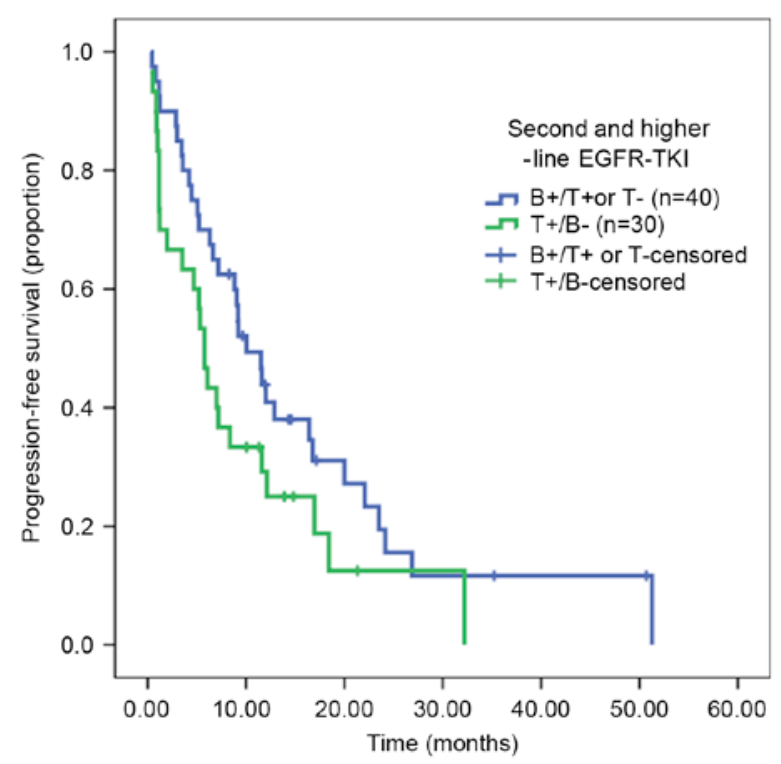

Figure 4. Progression-free survival curves for the 187 patients with different EGFR mutation statuses measured in tumor tissues and concurrent plasma DNA, who were treated by EGFR-TKIs as second-line or higher line therapy $(\mathrm{P}=0.044)$. EGFR, epidermal growth factor receptor; TKI, tyrosine kinase inhibitor; B-, wild-type EGFR gene in plasma DNA; T-, wild-type EGFR gene in tumor tissue; $\mathrm{B}+$, mutant type EGFR gene in plasma DNA; T+, mutant type EGFR gene in tumor tissue.

with EGFR mutations detected using real-time ctDNA (B+/T-) had a prolonged PFS compared with patients whose EGFR mutations were detected using initial tissue samples $(\mathrm{B}-/ \mathrm{T}+)$. These results suggest that EGFR mutations detected in the tissues and/or ctDNA may have different predictive values with regard to the response to EGFR-TKIs in different therapeutic backgrounds.

EGFR mutation status in ctDNA and the prediction of response to EGFR-TKIs has been extensively reported in international studies (10-12) and in our previous studies $(13,18)$. 
The results of the present study indicate that EGFR mutations detected in both the tissue and plasma $(\mathrm{B}+/ \mathrm{T}+)$ was better for predicting the benefit from first-line EGFR-TKI treatment in advanced NSCLC, compared with detection in a single specimen. Recent studies that investigated the effect of intratumor EGFR mutation heterogeneity on clinical outcomes following EGFR-TKI therapy have demonstrated that an increased abundance of intratumoral EGFR mutations (implying low heterogeneity) may lead to improved clinical outcomes compared to a low abundance of EGFR mutations (20). Although the release mechanism of ctDNA from tumor tissues to peripheral blood is not well understood, ctDNA is likely derived from apoptotic and necrotic tumor cells, including primary tumors, metastatic lesions or circulating tumor cells (21). Therefore, concurrent positive EGFR mutations in tissues and ctDNA may indicate that a large number of mutated cells in tumor tissues and fragments of dead cells are shed into the peripheral bloodstream, rendering EGFR mutations more easily detectable in ctDNA. Co-existence of EGFR mutations in tissues and ctDNA $(\mathrm{B}+/ \mathrm{T}+)$ indicates a high abundance of EGFR mutations, resulting in a good clinical outcome.

Notably, patients with EGFR mutations in ctDNA, regardless of the mutation status in tissues, tended to have a longer PFS time compared with B-/T+ patients who received EGFR-TKIs as second-line or subsequent therapy. One possible explanation for this trend is that the dynamic detection of EGFR mutations in plasma DNA may represent the actual EGFR mutation status post-treatment; although EGFR mutation detection in tissue obtained prior to initial treatment may have reasonable predictive value for first-line therapy, it may not reflect dynamic alterations to driver genes during treatment or disease progression $(18,22)$. If a repeat biopsy is difficult to obtain, either due to patient refusal or high medical risk, in patients with advanced NSCLC undergoing second-line or subsequent therapies, they may be advised to undergo biomarker detection in plasma DNA, which is helpful in making further clinical decisions.

In clinical practice, a relatively small proportion of patients had EGFR mutations only in ctDNA (B+/T-); this is probably because small biopsied specimens would be able to contain fewer cancer cell clones with EGFR mutations, and may not be detectable by routine assay. Due to therapeutic selective pressure, mutated cellular clones could proliferate and release ctDNA into the peripheral blood, resulting in positive detection of EGFR mutations in plasma DNA. In addition, tumor tissue heterogeneity may result in missed detection of EGFR mutations in some tumor samples (23), which can be supplemented by ctDNA from a different region of the tumor.

Primary and metastatic site biopsies are the preferred methods for determining tissue diagnosis in advanced patients. While surgical resection is always performed in early-stage patients, those with tumor tissues obtained by surgical resection in the current study did not have prolonged PFS times following EGFR-TKI therapy. Primary and metastatic site biopsies from $\mathrm{B}+/ \mathrm{T}$ - and $\mathrm{B}+/ \mathrm{T}+$ groups predicted a better response to EGFR-TKIs than biopsies from the B-/T+ group; however, this trend did not apply to resected tissues. Resected samples from early-stage surgeries may have different biological and genetic characteristics compared with advanced-stage metastatic tumor cells $(24,25)$. Another important factor is that adjuvant chemotherapy may influence EGFR mutation status (18). ctDNA is a favorable surrogate for patients who suffer from recurrence following surgical resection but are unable to undergo a repeat biopsy due to small tumor nodules or risky biopsy sites; ctDNA could provide more real-time biomarker information compared with tissues from early-stage surgical resections.

There are certain factors that limit the use of plasma DNA for EGFR mutation detection, including technical complexity, false negatives, turnaround time, and dilution of DNA derived from non-cancerous tissues. In the present study, the potential value of plasma DNA as a supplement or replacement for repeat biopsies in the dynamic, real-time detection of EGFR mutations was demonstrated; this could eventually develop into a validated direct method to precisely individualize EGFR-TKI management, via a prospective clinical study, such as the BENEFIT study (NCT02282267). The co-existence of EGFR mutations in both tissue and ctDNA may imply high content of EGFR mutations and therefore predict a longer PFS for NSCLC patients who receive EGFR-TKI therapy as first-line therapy.

\section{Acknowledgements}

The authors would like to thank Dr Ning Wang (Department of Imaging, Beijing Institute of Cancer Research, Beijing, China) for his contribution in reviewing computed tomography scans to assess tumor responses, Dr Zhonghu He (Department of Biochemistry, Beijing Institute of Cancer Research, Beijing, China) for assistance in statistical analysis, and Dr Yu Sun (Department of Pathology, Beijing Institute of Cancer Research, Beijing, China) for her efforts in pathological diagnosis. This work was supported by the National Natural Sciences Foundation Key Program (grant no. 81330062); the Education Ministry Innovative Research Team Program (grant no. IRT13003); the Peking University-Tsinghua University Joint Center for Life Sciences Clinical Investigator; the National High Technology Research and Development Program 863 (grant no. SS2015AA020403); the Beijing Technology Project (grant no. Z141100000214013); the Center for Molecular and Translational Medicine; the Special Research Fund for the Doctoral Program of Higher Education; the National Natural Sciences Foundation for Young Scholars (grant no. 81401914); the Wujieping Medicine Foundation (grant no. 320.6750.12192); Beijing Municipal Administration of Hospitals' Young Program (grant no. 20161112); Wu Jieping Medical Foundation Special Fund for Clinical Research (grant no. 320.6750.1361); and New Teachers Fund of the Chinese Ministry of Education (grant no. 20100001120124).

\section{References}

1. Siegel R, Naishadham D and Jemal A: Cancer statistics, 2013. CA Cancer J Clin 63: 11-30, 2013.

2. Molina JR, Yang P, Cassivi SD, Schild SE and Adjei AA: Non-small cell lung cancer: Epidemiology, risk factors, treatment, and survivorship. Mayo Clin Proc 83: 584-594, 2008.

3. Fukuoka M, Wu YL, Thongprasert S, Sunpaweravong P, Leong SS, Sriuranpong V, Chao TY, Nakagawa K, Chu DT, Saijo N, et al: Biomarker analyses and final overall survival results from a phase III, randomized, open-label, first-line study of gefitinib versus carboplatin/paclitaxel in clinically selected patients with advanced non-small-cell lung cancer in Asia (IPASS). J Clin Oncol 29: 2866-2874, 2011 
4. Garassino MC, Martelli O, Broggini M, Farina G, Veronese S, Rulli E, Bianchi F, Bettini A, Longo F, Moscetti L, et al: Erlotinib versus docetaxel as second-line treatment of patients with advanced non-small-cell lung cancer and wild-type EGFR tumours (TAILOR): A randomised controlled trial. Lancet Oncol 14: 981-988, 2013.

5. Zhang L, Ma S, Song X, Han B, Cheng Y, Huang C, Yang S, Liu X, Liu Y, Lu S, et al: Gefitinib versus placebo as maintenance therapy in patients with locally advanced or metastatic non-small-cell lung cancer (INFORM; C-TONG 0804): A multicentre, double-blind randomised phase 3 trial. Lancet Oncol 13: 466-475, 2012

6. Paez JG, Janne PA, Lee JC, Tracy S, Greulich H, Gabriel S, Herman P, Kaye FJ, Lindeman N, Boggon TJ, et al: EGFR mutations in lung cancer: Correlation with clinical response to gefitinib therapy. Science 304: 1497-1500, 2004.

7. Lynch TJ, Bell DW, Sordella R, Gurubhagavatula S, Okimoto RA, Brannigan BW, Harris PL, Haserlat SM, Supko JG, Haluska FG, et al: Activating mutations in the epidermal growth factor receptor underlying responsiveness of non-small-cell lung cancer to gefitinib. N Engl J Med 350: 2129-2139, 2004.

8. Pao W, Miller V, Zakowski M, Doherty J, Politi K, Sarkaria I, Singh B, Heelan R, Rusch V, Fulton L, et al: EGF receptor gene mutations are common in lung cancers from 'never smokers' and are associated with sensitivity of tumors to gefitinib and erlotinib. Proc Natl Acad Sci USA 101: 13306-13311, 2004.

9. Bell DW, Lynch TJ, Haserlat SM, Harris PL, Okimoto RA, Brannigan BW, Sgroi DC, Muir B, Riemenschneider MJ, Iacona RB, et al: Epidermal growth factor receptor mutations and gene amplification in non-small-cell lung cancer: Molecular analysis of the IDEAL/INTACT gefitinib trials. J Clin Oncol 23: 8081-8092, 2005.

10. Tsao MS, Sakurada A, Cutz JC, Zhu CQ, Kamel-Reid S, Squire J, Lorimer I, Zhang T, Liu N, Daneshmand M, et al: Erlotinib in lung cancer -molecular and clinical predictors of outcome. $\mathrm{N}$ Engl J Med 353: 133-144, 2005.

11. Kimura H, Suminoe M, Kasahara K, Sone T, Araya T, Tamori S, Koizumi F, Nishio K, Miyamoto K, Fujimura M and Nakao S: Evaluation of epidermal growth factor receptor mutation status in serum DNA as a predictor of response to gefitinib (IRESSA). Br J Cancer 97: 778-784, 2007

12. Rosell R, Moran T, Queralt C, Porta R, Cardenal F, Camps C, Majem M, Lopez-Vivanco G, Isla D, Provencio M, et al: Screening for epidermal growth factor receptor mutations in lung cancer. N Engl J Med 361: 958-967, 2009.

13. Bai H, Mao L, Wang HS, Zhao J, Yang L, An TT, Wang X, Duan CJ, Wu NM, Guo ZQ, et al: Epidermal growth factor receptor mutations in plasma DNA samples predict tumor response in Chinese patients with stages IIIB to IV non-small-cell lung cancer. J Clin Oncol 27: 2653-2659, 2009.

14. Weber B, Meldgaard P, Hager H, Wu L, Wei W, Tsai J, Khalil A, Nexo E and Sorensen BS: Detection of EGFR mutations in plasma and biopsies from non-small cell lung cancer patients by allele-specific PCR assays. BMC Cancer 14: 294, 2014.
15. Sozzi G, Conte D, Leon M, Ciricione R, Roz L, Ratcliffe C, Roz E, Cirenei N, Bellomi M, Pelosi G, et al: Quantification of free circulating DNA as a diagnostic marker in lung cancer. J Clin Oncol 21: 3902-3908, 2003.

16. Li X, Ren R, Ren S, Chen X, Cai W, Zhou F, Zhang Y, Su C, Zhao C, Li J, et al: Peripheral blood for epidermal growth factor receptor mutation detection in non-small cell lung cancer patients. Transl Oncol 7: 341-348, 2014.

17. Mok TS, Wu YL, Lee JS, Yu CJ, Sriuranpong V, Sandoval-Tan J, Ladrera G, Thongprasert S, Srimuninnimit V, Liao M, et al: Detection and dynamic changes of EGFR mutations from circulating tumor DNA as a predictor of survival outcomes in NSCLC patients treated with first-line intercalated Erlotinib and chemotherapy. Clin Cancer Res 21: 3196-3203, 2015.

18. Bai H, Wang Z, Chen K, Zhao J, Lee JJ, Wang S, Zhou Q, Zhuo M, Mao L, An T, et al: Influence of chemotherapy on EGFR mutation status among patients with non-small-cell lung cancer. J Clin Oncol 30: 3077-3083, 2012.

19. Sequist LV, Waltman BA, Dias-Santagata D, Digumarthy S, Turke AB, Fidias P, Bergethon K, Shaw AT, Gettinger S, Cosper AK, et al: Genotypic and histological evolution of lung cancers acquiring resistance to EGFR inhibitors. Sci Transl Med 3: 75ra26, 2011.

20. Zhou Q, Zhang XC, Chen ZH, Yin XL, Yang JJ, Xu CR, Yan HH, Chen HJ, Su J, Zhong WZ, et al: Relative abundance of EGFR mutations predicts benefit from gefitinib treatment for advanced non-small-cell lung cancer. J Clin Oncol 29: 3316-3321, 2011

21. Jahr S, Hentze H, Englisch S, Hardt D, Fackelmayer FO, Hesch RD and Knippers R: DNA fragments in the blood plasma of cancer patients: Quantitations and evidence for their origin from apoptotic and necrotic cells. Cancer Res 61: 1659-1665, 2001

22. Piotrowska Z, Niederst MJ, Karlovich CA, Wakelee HA, Neal JW, Mino-Kenudson M,Fulton L, Hata AN,Lockerman EL, Kalsy A, et al: Heterogeneity underlies the emergence of EGFR T790 wild-type clones following treatment of T790M-positive cancers with a third generation EGFR inhibitor. Cancer Discov 5: 713-722, 2015.

23. Bai H, Wang Z, Wang Y, Zhuo M, Zhou Q, Duan J, Yang L, Wu M, An T, Zhao J and Wang J: Detection and clinical significance of intratumoral EGFR mutational heterogeneity in Chinese patients with advanced non-small cell lung cancer. PloS One 8: e54170, 2013.

24. Han X, Zhang Z, Wu D, Shen Y, Wang S, Wang L, Liu Y, Yang S, Hu X, Feng Y, et al: Suitability of surgical tumor tissues, biopsy, or cytology samples for epidermal growth factor receptor mutation testing in non-small cell lung carcinoma based on chinese population. Transl Oncol 7: 795-799, 2014

25. Kim Y, Hammerman PS, Kim J, Yoon JA, Lee Y, Sun JM, Wilkerson MD, Pedamallu CS, Cibulskis K, Yoo YK, et al: Integrative and comparative genomic analysis of lung squamous cell carcinomas in East Asian patients. J Clin Oncol 32: 121-128, 2014. 